\title{
Helen Salisbury: Endgame for the NHS?
}

\author{
Helen Salisbury GP
}

Oxford

Since its foundation, the NHS has been committed to providing treatment according to clinical need. The distinction between want and need is important-there may be treatments that patients want but don't need, such as cosmetic surgery. In these cases, they have to go to the private sector and pay up front or through insurance. This is set out in the first two points of the NHS constitution, ${ }^{1}$ which state that the NHS provides a comprehensive service, available to all, and that access is based on clinical need, not a patient's ability to pay.

This week Warrington and Halton Hospitals NHS Trust was in the news for its published list of charges for 71 procedures. $^{2}$ This is not entirely new: starting with an initial offer of varicose vein surgery in $2013,{ }^{3}$ the scheme was relaunched in September 2018 with a hugely expanded list of procedures and has only now hit the headlines. This list appeared under the banner "My Choice—by the NHS, for the NHS," next to the NHS logo. This is very confusing and would leave many people asking, "Is this an NHS service or not?" The list included prices for cataract surgery (from $£ 2251$ ( $€ 2523 ; \$ 2872)$ ), knee replacement (from $£ 7179$ ), and hip replacement (from £7060), all of which are beyond the means of most people served by these hospitals, given Warrington's high deprivation. ${ }^{4}$

The justification given by the trust is that these procedures have been limited by NHS commissioners. ${ }^{5}$ Operations on this nationally generated list were initially referred to as "procedures of limited clinical value" and are now "criteria based clinical treatments." If patients don't meet the criteria but still want the surgery, they will have to pay.

This makes a mockery of the NHS constitution: either patients have a clinical need, in which case they should receive timely NHS care, or they don't need the surgery, in which case it's not in their interests to have it, and it shouldn't be done by the NHS. What this programme reveals is that access to procedures with a proven track record of safety and efficacy, which patients need in order to see clearly or move comfortably, is being denied. The "criteria" for many patients are increasingly stringent: the Royal College of Surgeons raised the alarm in 2017 about restricting hip and knee surgery on the basis of arbitrary pain and disability thresholds rather than clinical assessment. ${ }^{6}$ And cataract guidelines from the National Institute for Health and Care Excellence explicitly state that commissioners should not restrict access to surgery on the basis of visual acuity, ${ }^{7}$ yet that's what happens to patients covered by over a third of clinical commissioning groups. ${ }^{8}$ These decisions are not about optimising outcomes for patients but are a reaction to inadequate funding, requiring patients to be significantly visually impaired or disabled before they're treated.

Even more worrying is that an NHS trust is explicitly offering a two tier service, with earlier treatment if you can pay. We should resist this transformation from a single, comprehensive system, where all are treated equally, to one where rich patients have rapid access and poor patients struggle to be referred and then languish on waiting lists. Bevan must be turning in his grave.

Competing interests: See www.bmj.com/about-bmj/freelance-contributors. Provenance and peer review: Commissioned; not externally peer reviewed.

1 Department of Health and Social Care. Guidance: the NHS Constitution for England. Updated 14 Oct 2015. https://www.gov.uk/government/publications/the-nhs-constitutionfor-england/the-nhs-constitution-for-england.

2 Bagot M. NHS hospital demands $£ 18 \mathrm{k}$ for hip op as trust sells treatments that used to be free. Mirror 2019 Jun 9. https://www.mirror.co.uk/news/uk-news/nhs-hospital-demands18k-hip-16544619.

3 lacobucci G. A sixth of hospitals in England have expanded private patient options this year, the BMJ finds. BMJ 2013;347:f4524. 10.1136/bmj.f4524 23873920

4 Warrington Joint Strategic Needs Assessment. The English indices of deprivation 2015 Dec 2015. https://www.warrington.gov.uk/downloads/file/9153/jsna_2015_-_deprivation profile_imd_2015pdf.

5 Warrington and Halton Hospitals NHS Foundation Trust. My Choice service. Updated 20 Jun 2019. https://whh.nhs.uk/about-us/news-events-and-features/latest-news/my-choicecservice.

6 Royal College of Surgeons. RCS responds to CCGs' plans to ration hip and knee surgery using Oxford score. 27 Jan 2017. https://www.rcseng.ac.uk/news-and-events/mediacentre/press-releases/oxford-score-rationing/.

7 National Institute for Health and Care Excellence. Referral for cataract surgery. 2019 https://pathways.nice.org.uk/pathways/cataracts\#content=view-node\%3Anodes-referralfor-cataract-surgery.

8 Campbell D. NHS England restricts patients' access to cataract removal. Guardian 2019 Mar 20. https://www.theguardian.com/politics/2019/mar/20/nhs-england-restricts-patientsaccess-to-cataract-removal.

Published by the BMJ Publishing Group Limited. For permission to use (where not already granted under a licence) please go to http://group.bmj.com/group/rights-licensing/ permissions 